\title{
Perancangan Sistem Keamanan Brankas Menggunakan Metode Finger Print Berbasis SMS Gateway
}

\author{
Hanggoro Aji Al Kautsar ${ }^{1}$, Sri Watmah², Suryanto ${ }^{3}$ \\ 1,2,3 Universitas Bina Sarana Informatika \\ e-mail: ${ }^{1}$ hanggoro.hgr@bsi.ac.id, ${ }^{2}$ sriwatmah.wtm@bsi.ac.id, ${ }^{3}$ suryanto.syt@bsi.ac.id
}

\begin{abstract}
Abstrak - Bagi sebagian orang atau perusahaan memerlukan alat penyimpanan barang berharga dari bahaya pencurian/pembongkaran. Alat yang biasa digunakan untuk menyimpan barang berharga tersebut biasanya berupa brankas. Brankas merupakan lemari atau kotak besi yang digunakan untuk menyimpan barang berharga. Meskipun terbuat dari besi dan mempunyai kunci khusus brankas tetap perlu menggunakan teknologi untuk keamananya. Terlebih lagi sekarang marak terjadi pencurian. Sebagai solusi dari permasalahan ini maka maka dibutuhkan teknologi tempat penyimpanan barang berharga yang terintegrasi. Dalam penelitian ini penulis membuat sistem keamanan brankas menggunakan metode finger print berbasis sms gateway. Dengan penerapan sistem keamanan ganda yaitu dengan sidik jari sebagai akses untuk membuka pintu dan pemberitahuan melalui email jika bukan si pemilik yang membuka akses brankas tersebut. Sidik jari yang dapat digunakan untuk mengakses pintu brankas yaitu hanya sidik jari yang telah di rekam ke dalam sistem pengguna brankas sedangkan daya atau arus tegangan yang digunakan dalam keamanan ini menggunakan 9 Volt yaitu menggunakan sebuah adaptor 9 Volt.
\end{abstract}

Kata Kunci: Brankas, SMS Gateway, Finger Print.

Abstract - For some people or companies need a means of storing valuables from the danger of theft I demolition. Tools commonly used to store valuables are usually in the form of a safe. Safe is a cupboard or metal box that is used to store valuables. Even though it is made of iron and has a special lock, the safe still needs to use technology for its security. Especially now that theft is rampant. As a solution to this problem, an integrated technology for storing valuables is needed. In this study, the authors create a safe security system using a finger print method based on sms gateway. With the implementation of a dual security system, namely with fingerprints as access to open doors and notifications via email if it is not the owner who opens access to the safe. Fingerprints that can be used to access the safe door are only fingerprints that have been recorded into the safe user system while the power or voltage used in this security uses 9 Volts, namely using a 9 Volt adapter.

Keywords: Brankas, SMS gateway, finger print.

\section{PENDAHULUAN}

Brankas merupakan lemari atau kotak besi yang biasa dipergunakan untuk melindungi barang barang berharga dari bahaya pencurian/pembongkaran. Kunci pengaman pada brankas umumnya berdasarkan sistem kerjanya ada dua macam yaitu digital dan analog. Tidak jarang kedua sistem tersebut di satukan, brankas yang bersistem digital di sertai dengan kunci analog (kunci manual) serta terdapat brankas yang menggunakan 2 kunci analog (kunci kombinasi putar dan kunci panjang).

Mengingat banyaknya kasus pencurian terhadap barang berharga yang semakin meningkat. Pada umumnya brankas atau lemari pengaman yang ada sekarang kurang memiliki sistem keamanan yang baik dan penggunaan nomor kombinasi yang terkesan tidak praktis karena memerlukan waktu lama untuk menemukan nomer yang tepat. Berdasarkan permasalahan tersebut, maka dibutuhkan teknologi tempat penyimpanan barang berharga yang terintegrasi.

Berdasarkan hal tersebut terciptalah ide untuk merancang sistem keamanan brankas yang lebih aman sehingga diwujudkan dengan membuat sistem yang mengkombinasikan pengunci brankas menggunakan metode fingerprint berbasis SMS Gateway. Sehingga dapat memberikan informasi langsung ke pemilik tentang keadaan brangkas yang di akses yang memungkinkan pemilik mengetahui siapa yang telah mencoba mengakses brangkas tersebut yang diharapkan dapat memenuhi kebutuhan akan berangkas yang aman.

\section{METODE PENELITIAN}

Metode penelitian merupakan langkah penting dalam penyusunan tugas akhir khususnya bagi pembuatan alat. Di dalam kegiatan penelitian penulis melakukan pengumpulan data melalui dua cara. Yaitu metode pengamatan langsung (observation). Penulis 
melakukan pengamatan-pengamatan langsung terhadap para pengguna brangkas dan tidak lupa untuk melihat brangkas yang di miliki oleh penulis juga. Selain itu, penulis juga melakukan pengamatan melalui studi pustaka. Baik itu dengan membaca jurnal-jurnal terkait maupun dengan menonton aktifitas celah kemanan di media jejaring sosial berbagi video.

\section{HASIL DAN PEMBAHASAN}

\section{A. Tinjauan Umum Alat}

Alat yang kami rancang ini adalah sebuah alat untuk pengamanan sebuah mesin berangkas sama dengan doorlock atau pembuka pintu dengan sidik jari. Target kami disini adalah system ini bukan hanya tentang membuka pintu mesin berangkas dengan sidik jari saja namun pada setiap peregistrasian sidik jari . Ketika yang membuka mesin berangkas itu bukan si pemilik sidik jari yang terdaftar, maka system akan memberikan alert kepada sang pemilik ke SMS pemilik yang berisi notifikasi sebuah pesan seperti " Peringatan !! Ada yang berusaha membuka Berangkas Anda."

Alur program pada perancangan alat ini adalah pemilik berangkas melakukan registrasi terlebih dahulu. Yaitu dengan cara menempelkan jarinya di fingerprint. Setelah itu user id sidik jari tersebut akan masuk kedalam database yang telah kami buat. Lalu apabila ada sidik jari lain yang menempel pada fingerprint tersebut maka alat akan merespond dengan memeberikan notifikasi berupa pesan ke email pemilik berangkas.

\section{B. Blok Rangkaian Alat}

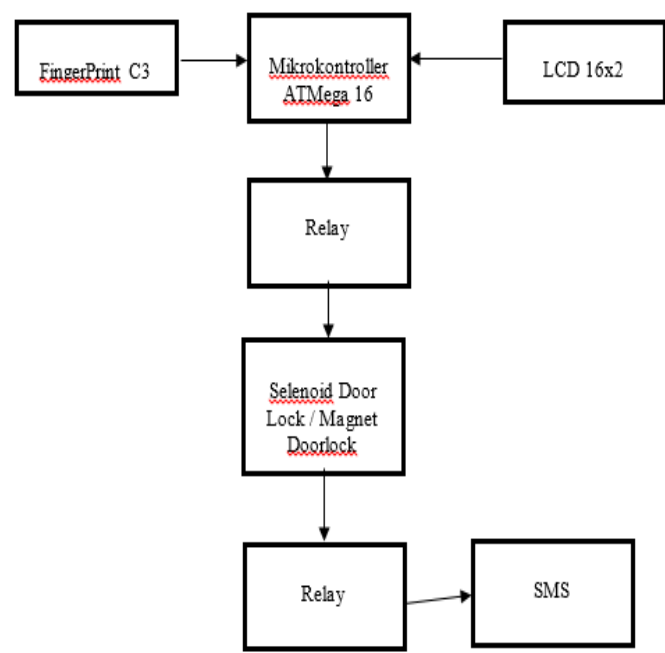

Sumber: Hasil Penelitian

Gambar I Blok Diagram Pengunci Brankas

Penjelasan blok diagram sebagai berikut :

1. Input

Komponen Input adalah komponen masukan yang akan di proses,komponen ini meliputi :

a. Adaptor yang akan memberikan tegangan atau arus
12 Volt 1 A kedalam rangkaian alat

b. Catu daya yang akan memberikan tegangan atau arus 5 volt kedalam rangkaian alat

c. Modul Relay sebagai daya pengontrol doorlock

d. Fingerprint digunakan akses membuka pintu berangkas.

\section{Proses}

Proses merupakan komponen utama yang berguna sebagai pengelola data yang diterima dari masukan yang kemudian akan menghasilkan keluaran atau output. Dalam proses ini penulis menggunakan Mikrokontroler ATMega16.

\section{Output}

Output merupakan proses ahir dari semua masukan yang telah dijalankan. Output yang dihasilkan yaitu :

a. Selenoid / Magnet DoorLock berfungsi sebagai indikator hasil input.

b. Fingerprint berfungsi sebagai pengendali membuka pintu berankas

\section{Skema Rangkaian Alat Suhu}

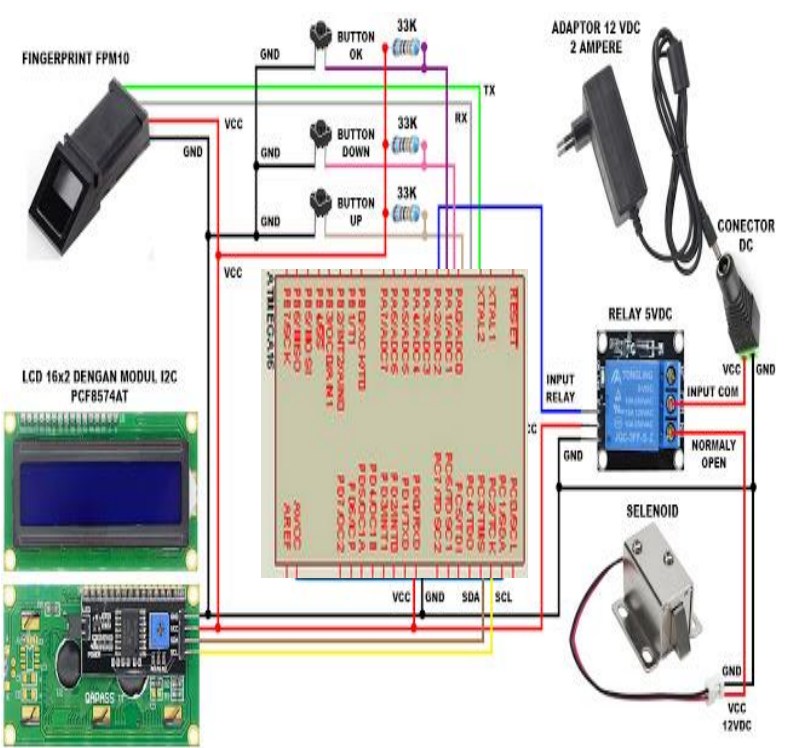

Sumber: Hasil Penelitian

Gambar II Skema Alat

Rancangan ini adalah system pengamanan Brankas yang menggunakan Mikrokontroller ATMega16 sebagai pusat pemroses data, kontrol relay dapat dimanfaatkan untuk penghubung membuka Doorlock, FingerPrint sebagai pengontrol atau pembacaan data untuk membuka Doorlock . Untuk pengontrolan sistem dibantu dengan jaringan wifi atau internet sebagai sarana komunikasi. Pengguna akan mendapatkan sebuah infomasi yang telah dibuat melalui Email ( Electronic Mail ).

\section{Cara Kerja Alat}

Sesuai dengan blok dan sekema rangkaian alat 
memiliki cara kerja yang berbeda. Berikut beberapa cara kerja alat yang akan diuraikan dibawah ini.

\section{Catu Daya}

Catu daya yang digunakan pada rangkaian alat yang panulis buat adalah adaptor 5 volt DC yang disambungkan dengan listrik rumah 220 volt AC kemudian di konvert menjadi tegangan output sebesar 5 volt DC.

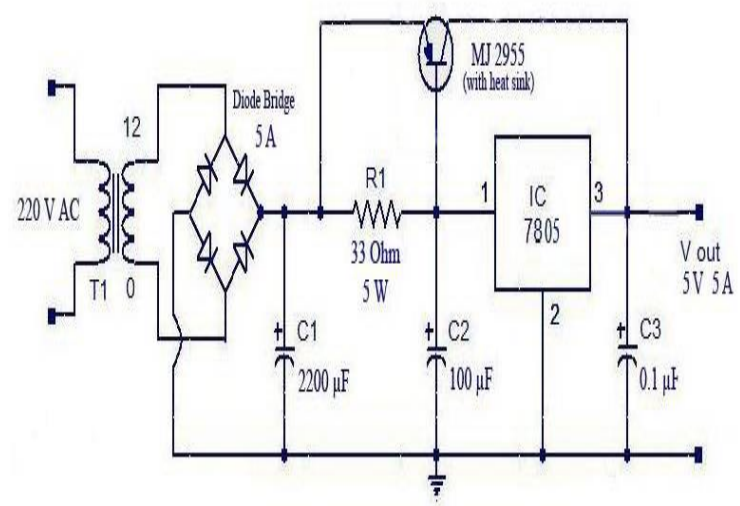

Sumber: Hasil Penelitian Gambar III Skema Blok Rangkaian

\section{ATMega 16}

ATMega16 merupakan bagian proses, yaitu memproses input menjadi output. ATMega16 memiliki 40 pin. Pada rangkaian suhu tubuh manusia otomatis pin yang digunakan adalah pin digital PD2 yang dihubungkan dengan sensor GY-906 MLX90614 dan pin digital PD3 yang disambungkan dengan LED sebagai pertanda adanya suhu yang terdeteksi. Untuk sumber tegangan menggunakan adaptor 5 volt yang disambungkan ke port micro usb. ATMega16 akan memperoses input yang dikirim dari Aplikasi firebase ke database selanjutnya akan mencocokan variable ke database untuk selanjutnya di proses menjadi output.

\section{Module Relay}

Relay adalah suatu komponen listrik yang berfungsi sebagai saklar ( Switch ) otomatis yang dioperasikan menggunakan listrik dan memiliki dua komponen elektro mekanis yaitu bagian utamanya berupa coil yang berfungsi sebagai komponen elektromagnet dan seperangkat kontak yang mewakili fungsi mekanis. Relay 4 Chanel ini memiliki 6 pin yang diantaranya 1 pin sebagai input VCC $0-5 \mathrm{vdc}$, lalu 1 pin GND, dan 4 pin input terdiri atas In 1 sampai dengan In 4 masing-masing relay memiliki beban sebesar 10A dan tegangan maksimal yang dapat mengalir di kontak adalah sebesar 250 Vac.(Prayudha, Pranata, and Prastyo 2020). Disini penulis menggunakan 1 buah relay dalam satu modul dan berfungsi sebagai saklar mekanik untuk membuka dan menutup kontak yang akan digunakan memutus dan menyambungkan yang akan mengalir ke selenoid. Relay akan menerima perintah dari porcessor dan Finger Print untuk membuka doorlock.

\section{E. Flowchart Program}

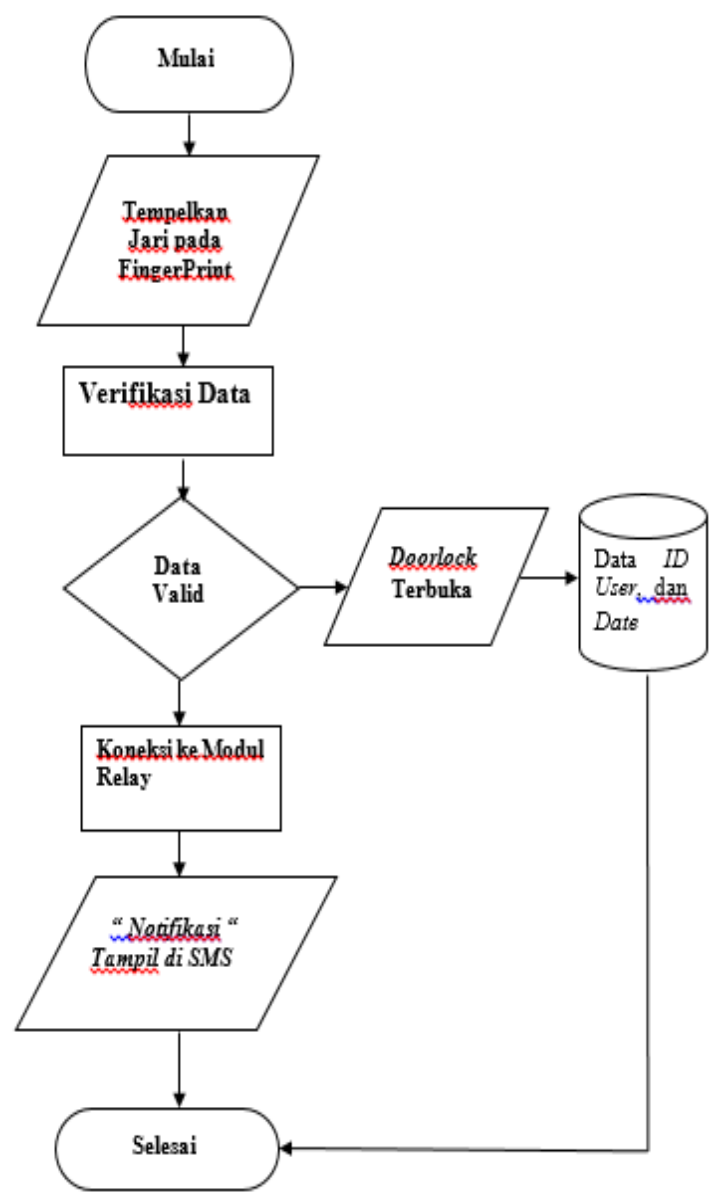

Sumber: Hasil Penelitian

Gambar IV Flowchart

\section{F. Konstruksi Sistem Coding}

\section{Input}

void $\operatorname{loop}()$ \{

// put your main code here, to run repeatedly:

lcd.setCursor $(0,0)$;

lcd.println("Waiting");

lcd.setCursor $(0,1)$;

lcd.println("FingerPrint");

pinMode(doorlock, OUTPUT);

digitalWrite(doorlock, LOW);

fingerprintID = getFingerprintIDez () ;

delay(60);

if (fingerprintID ==1)

Pada bahasa pemrograman $\mathrm{C}$ yang penulis gunakan, void loop merupakan fungsi pengulangan yang berfungsi untuk mengulang perintah. Fungsi ini untuk mengeksekusi bagian program yang akan dijalankan berulang-ulang.

\section{Main Program}

void setup() \{

// put your setup code here, to run once:

Serial.begin(3600); 
finger.begin(59600);

Fungsi void setup hanya dipanggil satu kali ketika program pertama kali dijalankan. Ini digunakan untuk mendefinisikan mode pin atau memulai komunikasi serial.

\section{Output}

void setup() \{

// put your setup code here, to run once:

Serial.begin(9600);

finger.begin(57600);

//lcd setup

lcd.begin();

lcd.backlight();

if (finger.verifyPassword())

\{

lcd.setCursor $(0,0)$;

Serial.println("Sensor Terdeteksi");

lcd.print("Sensor Terdeteksi");

delay (500);

lcd.clear();

\}

else \{

Serial.println("no sensor :(");

lcd.setCursor $(0,0)$;

lcd.print(" No Sensor :(");

delay(500);

lcd.clear();

while (1) $\{$ delay $(1)$; $\}$

\}

lcd.setCursor $(0,0)$;

lcd.print ("Tugas Akhir");

lcd.setCursor $(0,1)$;

lcd.print("FingerPrint");

delay (3000);

lcd.clear();

Serial.begin(3600);

delay(10);

Serial.println();

Serial.println();

Serial.print("Connecting process ");

Serial.println(find);

cont.begin(ssid, password);

while (cont.status() !=WL_CONNECTED) \{

delay (100);

Serial.print(".");

\}

Serial.print("");

Serial.println("Connected");

Serial.println("Address: ");

Serial.println(localloop());

\}

\section{G. Hasil Percobaan}

Hasil percobaan alat terdiri dari 2 bagian hasil percobaan yaitu :

1. Input

Pengujian sistem FingerPrint, pengujian ini dilakukan untuk memastikan bahwa mesin FingerPrint dapat membaca validasi data sidik jari, dimulai dari pembacaan sidik jari yang telah terdaftar sampai percobaan pembacaan sidik jari yang belum terdaftar. Dan berikut adalah hasil dari pengujian tersebut.

Tabel I Percobaan Input

\begin{tabular}{|c|l|c|c|c|}
\hline No & Pengujian Sidik Jari & $\begin{array}{c}\text { Terdaftar/ } \\
\text { Tidak }\end{array}$ & Hasil & Kesimpulan \\
\hline 1 & Ibu Jari & $\begin{array}{c}\text { Terdaftar } \\
\text { sebagai admin }\end{array}$ & Brankas terbuka & Berhasil \\
\hline 2 & Jari Telunjuk & $\begin{array}{c}\text { Terdaftar } \\
\text { sebagai admin }\end{array}$ & Brankas terbuka & Berhasil \\
\hline 3 & Jari manis & $\begin{array}{c}\text { Tidak } \\
\text { Terdaftar }\end{array}$ & $\begin{array}{c}\text { Brangkas tidak } \\
\text { terbuka }\end{array}$ & Berhasil \\
\hline 4 & Jari Tengah & $\begin{array}{c}\text { Tidak } \\
\text { Terdaftar }\end{array}$ & $\begin{array}{c}\text { Brangkas tidak } \\
\text { terbuka }\end{array}$ & Berhasil \\
\hline 5 & Jari Kelingking & $\begin{array}{r}\text { Tidak } \\
\text { Terdaftar }\end{array}$ & $\begin{array}{c}\text { Brangkas tidak } \\
\text { terbuka }\end{array}$ & Berhasil \\
\hline
\end{tabular}

Sumber: Hasil Penelitian

\section{Output}

Untuk hasil pengujian output ini, saat pengujian validasi sidik jari di lakukan maka sistem pada Mikrokontroller ATMega16 akan membaca kedalam database, hasilnya sebagai berikut :

Tabel II Percobaan Output

\begin{tabular}{|c|c|c|c|c|c|c|}
\hline No & Fingerprint & $\begin{array}{c}\text { Terdaftar/ } \\
\text { Tidak }\end{array}$ & $\begin{array}{c}\text { Lcd } \\
16 \times 2\end{array}$ & DoorLock & SMS & DataBase \\
\hline 1 & Ibu Jari & $\begin{array}{c}\text { Terdaftar } \\
\text { sebagai } \\
\text { admin }\end{array}$ & Tampil & Pintu terbuka & $\begin{array}{c}\text { Tidak } \\
\text { memberikan } \\
\text { notifikasi }\end{array}$ & Ya \\
\hline 2 & $\begin{array}{l}\text { Jari } \\
\text { Telunjuk }\end{array}$ & $\begin{array}{c}\text { Terdaftar } \\
\text { sebagai } \\
\text { admin } \\
\end{array}$ & Tampil & Pintu terbuka & $\begin{array}{c}\text { Tidak } \\
\text { memberikan } \\
\text { notifikasi }\end{array}$ & Ya \\
\hline 3 & Jari manis & $\begin{array}{c}\text { Tidak } \\
\text { Terdaftar }\end{array}$ & $\begin{array}{l}\text { Tidak } \\
\text { Tampil }\end{array}$ & $\begin{array}{l}\text { Pintu tidak } \\
\text { terbuka }\end{array}$ & $\begin{array}{c}\text { Memberikan } \\
\text { notifikasi }\end{array}$ & Tidak \\
\hline 4 & Jari Tengah & $\begin{array}{c}\text { Tidak } \\
\text { Terdaftar }\end{array}$ & $\begin{array}{l}\text { Tidak } \\
\text { Tampil }\end{array}$ & $\begin{array}{l}\text { Pintu tidak } \\
\text { terbuka }\end{array}$ & $\begin{array}{c}\text { Memberikan } \\
\text { notifikasi }\end{array}$ & Tidak \\
\hline 5 & $\begin{array}{l}\text { Jari } \\
\text { Kelingking }\end{array}$ & $\begin{array}{c}\text { Tidak } \\
\text { Terdaftar }\end{array}$ & $\begin{array}{l}\text { Tidak } \\
\text { Tampil }\end{array}$ & $\begin{array}{c}\text { Pintu tidak } \\
\text { terbuka }\end{array}$ & $\begin{array}{c}\text { Memberikan } \\
\text { notifikasi }\end{array}$ & Tidak \\
\hline 6 & $\begin{array}{l}\text { Jari } \\
\text { memakai } \\
\text { sarung } \\
\text { tangan }\end{array}$ & $\begin{array}{c}\text { Tidak } \\
\text { Terdaftar }\end{array}$ & $\begin{array}{l}\text { Tidak } \\
\text { Tampil }\end{array}$ & $\begin{array}{l}\text { Pintu tidak } \\
\text { terbuka }\end{array}$ & $\begin{array}{c}\text { Tidak } \\
\text { memberikan } \\
\text { notifikasi }\end{array}$ & Tidak \\
\hline
\end{tabular}

Sumber: Hasil Penelitian

Hasil di atas merupakan hasil pengujian alat yang penulis lakukan, jika sidik jari di tempelkan pada mesin fingerprint dan terdeteksi valid, maka sensor doorlock pada pintu brankas akan terbuka dan data id user dan waktu tersimpan di database, namun jika sidik jari tidak terdeteksi maka akan ada notifikasi peringatan ke SMS pemilik. 


\section{KESIMPULAN}

Berdasarkan Sistem Keamanan Mesin Brangkas yang telah kami buat dapat diambil kesimpulan sebagai berikut:

1. Pembuatan alat keamanan brankas telah selesai di rangkai, dan sistem ini memiliki keamanan ganda yaitu dengan sidik jari sebagai akses untuk membuka pintu dan pemberitahuan melalui email jika bukan si pemilik yang membuka akses brankas tersebut.

2. Pintu brankas ini hanya dapat di buka dengan menggunakan sidik jari yang terlebih dahulu di rekam ke dalam sistem pengguna brankas.

3. Sistem keamanan ini menggunakan daya atau arus tegangan 9 Volt yaitu menggunakan sebuah adaptor 9 Volt.

Untuk pengembangan alat ini, kedepan bisa menggunakan mikrokontroller berbasis IoT atau menggunakan modul arduino. Karena pada kedua modul tersebut, lebih banyak lagi perangkat yang dapat terhubung. Sehingga di harapkan sistem keamanan alat ini dapat lebih terpercaya lagi.

\section{REFERENSI}

Abdul Muin Hasan Busri, R.Helal Soekartono, dan Sri Yogyarti. Vol 59. 2010. Rancang Bangun Mikrokontroler AT89S51 Sebagai Alat Ukur Kekuatan Gigi. ISSN 0024-9548.

Abdulkadom Alyasiri, Jameel K Abed, Mohannad Jinnati. Vol 3.2014. Design and Implementation New Saving Energy System by Using Human Motion Sensor. ISSN : 22783075

Andrianto, Heri. 2015. Pemograman Mikrokontroler AVR Atmega 16. Bandung: Informatika Bandung.

A Annisya, L Hermanto, R Candra. 2019. 2018. 2020. "Sistem keamanan buka tutup kunci brankas menggunakan sidik jari berbasis arduino mega"

Budiharto, Widodo.2006. Belajar Sendiri 12 Proyek Mikrokontroler Untuk Pemula.Jakarta. PT Elex Media Komputindo.

Chandra, F., dan Deni Arifianto. 2010. Jago Elektronika. Jakarta: Kawan Pustaka.

Daryanto. 2011. Keterampilan Kejuruan Teknik Elektronik. Bandung: Satu Nusa.

Ratnadewi, Agus Prijono, Yohana Susanthi. 2015. Dasar-dasar Rangkaian Listrik. Bandung: C.V ALFABETA.

Saiyari, Hafdaiarsya Noviansyah, Mohammad. 2019. "SISTEM INFORMASI KEAMANAN BRANKAS DENGAN MIKROKONTROLER ATMEGA 16"

Sasongko, Bagus Hari. 2012. Pemrograman Mikrokontroler dengan Bahasa C. Yogyakarta:

\section{C.V Andi Offset.}

Suyadhi, Taufiq Dwi Septian. 2010. Buku Pintar Robotika. Yogyakarta: Andi.

Syaryadhi, mohd., et al. 2007. Sistem keran wudhu menggunakan sensor PIR berbasis mikrokontroler AT89C51 jumlah rekayasa elektronika vol. 6 No. 1 hlm.

Wibawanto, Hari. 2008. Elektronika Dasar : Pengenalan Praktis. Jakarta: PT Elex Media Komputindo.

Winoto, Ardi. 2010. Mikrokontroler AVR Atmega8/16/8535 dan Pemogramannya dengan Bahasa $\mathrm{C}$ pada WinAVR. Bandung: Informatika Bandung. 